\title{
Qidong hepatitis B virus infection cohort: a 25-year prospective study in high risk area of primary liver cancer
}

\author{
Tao-Yang Chen"\#, Geng-Sun Qiann", Chun-Sun Fan, ${ }^{1,2}$, Yan Sun 1 , Jin-Bing Wang', Pei-Xin Lu', Xue-Feng \\ Xue', Yan Wu', Qi-Nan Zhang', Yan Jin², Yi-Qian Wu'2, Yu Gan², Jian-Quan Lu', Thomas W. Kensler ${ }^{3}$, John \\ D. Groopman ${ }^{3}$, Hong $\mathrm{Tu}^{2}$
}

\begin{abstract}
'Department of Etiology, Qidong Liver Cancer Institute, Qidong People's Hospital, Qidong 226200, Jiangsu, China. ${ }^{2}$ State Key Laboratory of Oncogenes and Related Genes, Shanghai Cancer Institute, Renji Hospital, Shanghai Jiao Tong University School of Medicine, Shanghai 200032, China.

${ }^{3}$ Environmental Health and Engineering, Bloomberg School of Public Health, Johns Hopkins University, Baltimore, MD 21205, USA.

\#Contribute equally to this work.
\end{abstract}

Correspondence to: Dr. Hong Tu, State Key Laboratory of Oncogenes and Related Genes, Shanghai Cancer Institute, Renji Hospital, Shanghai Jiao Tong University School of Medicine, Shanghai 200032, China. E-mail: tuhong@shsci.org

How to cite this article: Chen TY, Qian GS, Fan CS, Sun Y, Wang JB, Lu PX, Xue XF, Wu Y, Zhang QN, Jin Y, Wu YQ, Gan Y, Lu JQ, Kensler TW, Groopman JD, Tu H. Qidong hepatitis B virus infection cohort: a 25-year prospective study in high risk area of primary liver cancer. Hepatoma Res 2018;4:4. http://dx.doi.org/10.20517/2394-5079.2017.50

Received: 30 Nov 2017 First Decision: 21 Dec 2017 Revised: 18 Jan 2018 Accepted: 19 Jan 2018 Published: 26 Jan 2018

Science Editor: Guang-Wen Cao Copy Editor: Jun-Yao Li Production Editor: Cai-Hong Wang

\begin{abstract}
Qidong hepatitis B virus (HBV) infection cohort (QBC) is a prospective community-based study designed to investigate causative factors of primary liver cancer (PLC) in Qidong, China, where both PLC and HBV infection are highly endemic. Residents aged 20-65 years, living in seven townships of Qidong, were surveyed using hepatitis B surface antigen ( $\mathrm{HBs} A g$ ) serum test and invited to participate in QBC from June 1991 to December 1991. A total of 852 and 786 participants were enrolled in HBsAg-positive and HBsAg-negative sub-cohorts in May 1992, respectively. All participants were actively followed up in person, received $\mathrm{HBsAg}$, alanine aminotransferase, alpha-fetoprotein tests and upper abdominal ultrasonic examination, and donated blood and urine samples once or twice a year. The total response rate was $99.6 \%$, and the number of incident PLC was 201 till the end of February 2017. The ratio of incidence rates was 12.32 [95\% confidence interval (CI): 7.16-21.21, $P<0.0001]$ in HBsAg-positive arm compared with HBsAg-negative arm. The relative risk of PLC was 13.25 (95\% $\mathrm{Cl}$ : 6.67-26.33, $P<0.0001)$ and $28.05(95 \% \mathrm{Cl}: 13.87-56.73, P<0.0001)$ in the $\mathrm{HBsAg}^{+} / \mathrm{HBeAg}^{-}$group and the $\mathrm{HBsAg}^{+} /$ $\mathrm{HBeAg}^{+}$group, respectively, as compared to the $\mathrm{HBsAg} / \mathrm{HBeAg}$ group. A series of novel PLC-related mutations including A2159G, A2189C and G2203W at the C gene, A799G, A987G and T1055A at the P gene of HBV genome were identified by using samples from the cohort. The mutation in HBV basal core promoter region of HBV genome has an accumulative effect on the occurrence of PLC. In addition, the tripartite relationship of aflatoxin exposure, P53 mutation and PLC was also
\end{abstract}

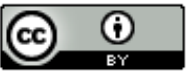

(C) The Author(s) 2018. Open Access This article is licensed under a Creative Commons Attribution 4.0 International License (https://creativecommons.org/licenses/by/4.0/), which permits unrestricted use, sharing, adaptation, distribution and reproduction in any medium or format, for any purpose, even commercially, as long as you give appropriate credit to the original author(s) and the source, provide a link to the Creative Commons license, and indicate if changes were made.

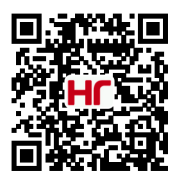


investigated. QBC will be used to develop dynamic prediction model for PLC risk by using its long-term follow-up information and serial blood samples. This model is expected to improve the efficiency of PLC screening in HBV infection individuals.

Keywords: Prospective cohort, hepatitis B virus, primary liver cancer

\section{HOW WAS THE STUDY INITIATED?}

Qidong City, named Qidong County before 1989, is located on the north shore of the Yangtze River and has a population of approximately 1.1 million. In the Early 1970s, a population-based retrospective survey on cancer mortality revealed that the mortality rate ascribed to primary liver cancer (PLC) in Qidong was $49.04 / 10^{5}$, placing PLC as the leading cause of cancer mortality in Qidong. This also exceeded the rates of all other areas in eastern China ${ }^{[1]}$. Subsequently, a national population-based incidence survey conducted during 1983 to 1987 showed that the PLC incidence rate in Qidong was 85.1/10 in males and 23.3/10 in females, respectively ${ }^{[2]}$, both being in the top rank across mainland China. "Qidong high incidence area of liver cancer" became known worldwide subsequently. Two retrospective cohort studies in Qidong indicated that hepatitis B virus (HBV) was a major risk factor contributing to PLC risk with relative risk of $17.4^{[3]}$ and $5.93^{[4]}$. Other etiological factors had also been suggested to explain the endemic of PLC in Qidong, including dietary aflatoxin contamination ${ }^{[5]}$, selenium deficiency ${ }^{[6]}$, and drinking water polluted by blue green algal toxins ${ }^{[7]}$. However, the magnitude of the contribution of each etiologic factor to the endemic of PLC and the role of potential synergistic interactions among these factors were uncertain. In order to extensively investigate the relationship between HBV infection and PLC endemic, and collect serial bio-samples of cohort members which were not available from the previous cohorts in Qidong, investigators from Shanghai Cancer Institute and Qidong Liver Cancer Institute initiated a prospective cohort study named "Qidong Hepatitis B Virus Infection Cohort (QBC)" in 1991. Later on, a research team from John Hopkins University joined in the beginning of 1994. The QBC aimed to recruit participants positive with serum hepatitis B surface antigen (HBsAg) as the exposure group and those who were HBsAg negative as the non-exposure group, and then to observe prospectively PLC occurrence as the primary outcome. Bio-samples were collected periodically for analysis of the kinetic changes of viral and host factors during the natural history of HBV infection. The study protocol and informed consent were approved by the human subjects review committees at the Qidong Liver Cancer Institute, Shanghai Cancer Institute and John Hopkins University.

\section{WHAT DOES THE STUDY COVER?}

The overarching goal of the QBC was to elucidate the causative factors of PLC and to identify effective measures to prevent this lethal malignancy. Initially, the $\mathrm{QBC}$ focused on understanding the proportion of HBV infection contributing to the endemic of PLC in Qidong. Later, taking advantage of serial plasma samples, the QBC was expanded to explore the interactions between HBV and aflatoxin exposure as well as to probe associations of aflatoxin metabolism or metabolizing enzymes with PLC. Additionally, several molecular epidemiologic studies were carried out to understand the relationship between HBV variations and PLC occurrence in order to identify new molecular biomarkers for early detection or prediction of PLC utilizing stored pre-diagnostic plasma samples. Meanwhile, a bio-specimen bank containing longitudinally collected blood, urine, liver tissues was established successfully.

\section{WHO WAS IN THE STUDY?}

Residents living in the Haidong district of Qidong City, which included 7 towns named "Haifu**", "Jinhai", "Xiangyang", "Juyang", "Shaozhi", "Dongyuan", and "Hefeng*”, were considered as potential participants [Figure 1]. In the 1980s-1990s, the total number of residents in each of these towns was approximately 15,000, representing the PLC endemic population of Qidong ${ }^{[8]}$. From June 1991 to December 1991, local physicians carried out door to door visits, asking questions about medical history of viral hepatitis. Residents aged 2065 years who claimed to have a history of acute or chronic hepatitis, or who were HBsAg positive in past 


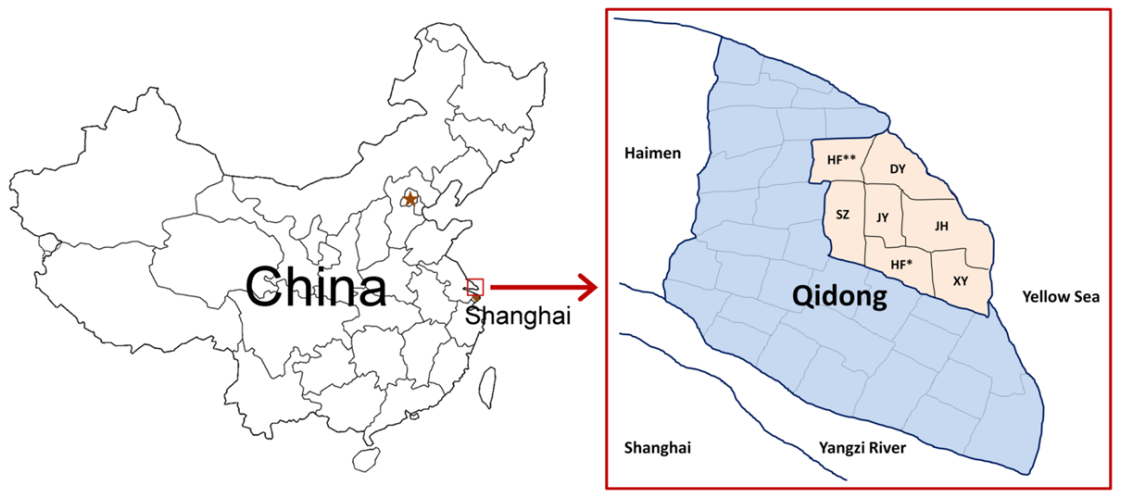

Figure 1. Location of the participants in the Qidong hepatitis B virus infection cohort

screenings during physical examination were regarded as potential candidates. A total of 1157 potential candidates were identified and invited for HBsAg testing by the ELISA kit from Shanghai Kehua Bioengineering Co., Ltd (KHB) within the following 6 months to confirm their HBsAg carrier status. Only those who were confirmed to be HBsAg positive in the second-round test and who signed the informed consent were enrolled into the study as participants in the HBV exposed sub-cohort. Meanwhile, local residents who claimed no history of hepatitis and who tested negative for HBsAg with a similar distribution of age, gender, living habits (type of drinking water and staple food), and living places were invited to participate in the HBV unexposed sub-cohort upon receiving their signed consent. Exclusion criteria were the same for both sub-cohorts, including those who had been diagnosed with cancer of any site, or who subsequently died within the first 12 months after enrollment into the cohort [Figure 2]. The final number of the participants in HBsAg positive and HBsAg negative sub-cohorts in May 1992 were 852 and 786, respectively. The mean age of HBsAg-positive participants was $37.06 \pm 11.24$ years (251 in below 30 years group (group I), 301 in between 30-40 years group (group II), 300 in above 40 years group (group III); while the mean age of HBsAg-negative participants was $41.20 \pm 12.12$ years (158 in group I, 237 in group II, 391 in group III). The male to female ratios in HBsAg-positive group was 5.45:1, and in HBsAg-negative group was 6.08:1.

\section{HOW OFTEN WAS THE FOLLOW-UP?}

All participants were followed up at least once every year. From 2009 to 2017, those who were HBsAg positive and had one of the following conditions: $\alpha$-fetoprotein (AFP, tested by KHB ELISA Kit) and alanine aminotransferase (ALT) (tested by dinitrophenylhydrazine method using KHB reagent) higher than normal value, or abnormal liver ultrasound (GE Healthcare) findings such as liver nodule and liver cirrhosis, were followed every 6 months. The annual active follow-ups were usually conducted in April and October, while non-respondents were tracked during the traditional Chinese Lunar New Year to guarantee a high response rate. Subjects who presented symptoms such as indigestion, jaundice, or discomfort in hepatic zones were immediately arranged to receive upper abdomen ultrasonic screening and recheck of serum AFP levels. Each participant continues to have free access to clinics affiliated with the Qidong Liver Cancer Institute to receive a free physical examination if he/she felt any discomfort or experienced any indisposed symptoms.

The occurrence of PLC was found not only by the routine active follow-up, but also by annual data linkage with the Qidong Cancer Registry, a well-maintained population-based cancer registry ${ }^{[9]}$. For deceased individuals, death certificates were requested from the Qidong Death Registry, another population-based registry in Qidong. Non-responders were regularly contacted by both staff members of the QBC and local physicians until participants were confirmed to have withdrawn. With such active and passive follow-up, loss to follow-up only occurred when participants migrated out of Qidong and failed to respond. Since the 


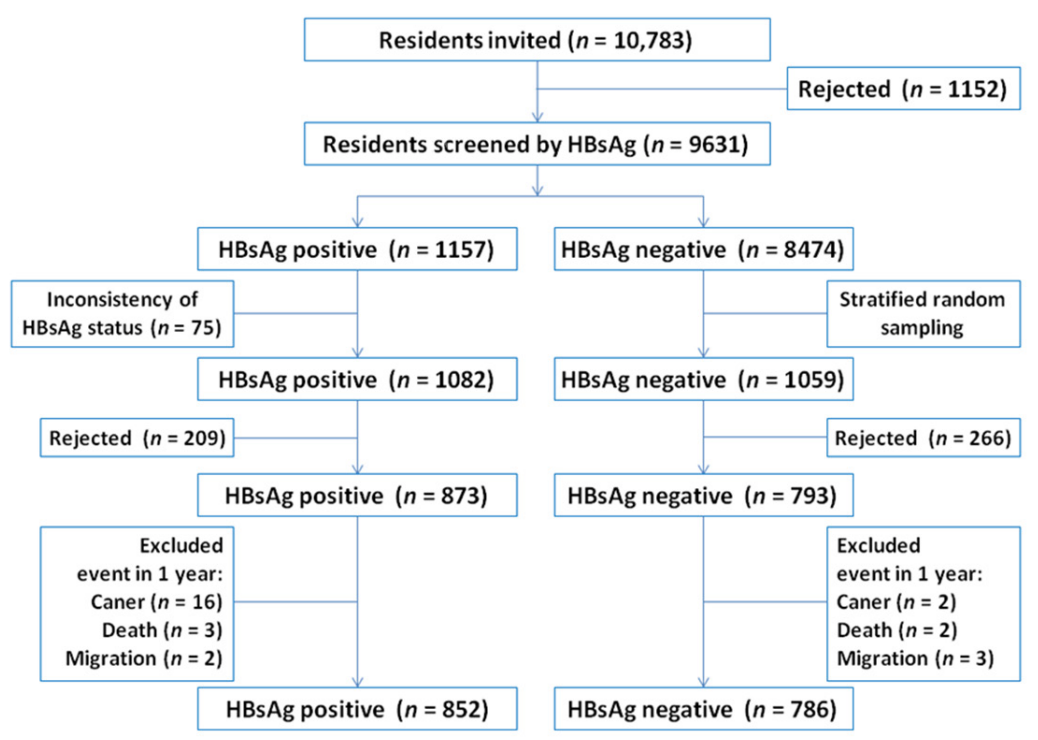

Figure 2. Flow chart for enrollment of participants into Qidong hepatitis B virus infection cohort. HBsAg: hepatitis B surface antigen

migration rate of the local population older than their 30s is low, attrition from the QBC was rare. The total response rate as of the end of February 2017 was $99.6 \%$.

To construct a bio-bank to facilitate future research, blood samples were collected both at baseline and during every follow-up. Plasma and white blood cells were divided into aliquots and stored under appropriate conditions at the Shanghai Cancer Institute, the Qidong Liver Cancer Institute, and the John Hopkins University. Their coding system was the same as preserved in the Qidong Liver Cancer Institute. As of February 2017, a total of 23,815 plasma samples, 17,581 urine samples and 17,581 white blood cells from cohort members were acquired and properly stored. There were 1453, 1163, 815 and 144 participants donating serial plasma samples of more than 5, 10, 15 and 20 years' duration, respectively. Apart from body fluid and blood samples, 35 tumor tissue samples and adjacent non-tumor liver tissues from PLC incident cases within the QBC were well preserved in liquid nitrogen as well.

\section{WHAT HAS BEEN MEASURED?}

\section{Questionnaires}

At the baseline survey between 1991 and 1992 certified doctors and nurses with the aid of trained local physicians conducted the personal interviews by asking information on socio-demographic characteristics and past medical history. A standardized, structured questionnaire completed through face to face interviews was administrated in 1998 and covered all participants. The questions included socio-demographic data, dietary habits, type of drinking water, consumption of alcohol, tea, and tobacco, past medical history and present medical condition, family history of cancer, menstrual and reproductive history (females only), and vaccination history. In 2012, an updated questionnaire was implemented, and some new variables such as history of diabetes and use of antiviral therapy in members of the HBV exposed sub-cohort were also documented. Brief items and variables of both structured questionnaires were illustrated in Table 1.

\section{Physical examination and blood tests}

During each follow-up, height, weight, and blood pressure were measured and recorded. Laboratory tests for HBsAg, ALT, and AFP and upper abdominal ultrasonic exam were also performed at least once a year between 1992 and 2017. Antibody to hepatitis C virus (HCV) was measured in 2009 to determine the rate of co-infection of HBV and HCV. In the 2009 and 2012 follow-ups, HBV serum markers, including HBsAg, 
Table 1. Key variables of structure questionnaires

\begin{tabular}{ll}
\hline Baseline questionnaires (1998) & Updated questionnaires (2012) \\
\hline Unique code & Occupation \\
Name & Family size \\
Gender & Family income \\
ID code (containing birth date and gender) & Temporary place \\
Occupation & Staple food \\
Home address & Drinking water \\
Employer & Alcohol drinking \\
Phone call & Tea drinking \\
Birth place & Smoking \\
Education & Medical history \\
Marital status & Family history of cancer \\
Financial condition & Family history of HCC \\
Staple food & Diabetes history \\
Drinking water & High blood pressure history \\
Tobacco consumption & \\
Alcohol drinking & \\
Tea drinking & \\
Medical history & \\
Menstrual and reproductive history (if female) & \\
Vaccination history & \\
Prophylactic intervention & \\
\hline
\end{tabular}

HCC: hepatocellular carcinoma

antibody to hepatitis B surface antigen, hepatitis B e antigen, antibody to hepatitis B e antigen, and antibody to hepatitis B core antigen, as well as urine glucose, and fasting blood glucose were also measured. In particular, baseline HBV DNA load, a well acknowledged viral parameter, was surveyed by using cryopreserved plasma samples between 2014 and 2015.

\section{Other parameters based on nested case-control design}

Several nested case-control studies have been carried out by using samples collected in the QBC. Exposure biomarkers and genetic variation markers measured were determined for some of the study participants, including aflatoxin metabolism ${ }^{[10]}$, aflatoxin-albumin adducts ${ }^{[11]}$, polymorphism of Glutathione S-Transferase $\mathrm{T} 1$ and $\mathrm{M} 1^{[12]}$, epoxide hydrolase ${ }^{[13]}$, xeroderma pigmentosum group $\mathrm{D}^{[14]}$, codon 249 mutation of $\mathrm{p} 53$, loss of heterozygosity at chromosome $4 \mathrm{q}^{[15]}$, HBV genotype and versatile HBV mutations in X gene ${ }^{[16-20]}$, S gene $\mathrm{e}^{[21]}$, C gene $^{[22,23]}$, and P gene ${ }^{[24-27]}$ of HBV genome.

\section{WHAT HAS BEEN FOUND?}

\section{HBV infection and PLC endemic in Qidong}

By the end of February 2017, after a median follow-up duration of 24.83 years, a total of 201 incident PLC cases were identified in the QBC. PLC was the most common cancer type, comprising more than $65 \%(201 / 304)$ of all cancer cases. PLC incidence in the HBV exposed sub-cohort was significantly higher than that of the HBV nonexposed sub-cohort with an incidence rate ratio (IRR) of 12.32 (95\% CI: 7.16-21.21, $P<0.0001$ ). No other statistically significant IRR were observed on any other cancers including lung, gastric, colorectal etc. [Table 2]. These findings, in addition to our previous publications on the QBC, define HBV infection as the most important etiologic factor for explaining the PLC epidemic in Qidong ${ }^{[28-30]}$.

Furthermore, we have explored the association between HBeAg status, HBV DNA load and PLC risk in the HBV exposed sub-cohort. We found that the relative risk of PLC was 13.25 (95\% CI: 6.67-26.33, $P<0.0001$ ) and 28.05 (95\% CI: 13.87-56.73, $P<0.0001$ ) in the $\mathrm{HBsAg}^{+} / \mathrm{HBeAg}^{-}$group and the $\mathrm{HBsAg}^{+} / \mathrm{HBeAg}^{+}$group, respectively, as compared to the $\mathrm{HBsAg} / \mathrm{HBeAg}$ group ${ }^{[31,32]}$. Those with levels of HBV DNA more than 250 copies/mL had a 4.78 -fold risk of PLC compared to those without detectable HBV DNA. The HBsAg carriers with serum HBV DNA between $10^{5}$ and $10^{6}$ copies $/ \mathrm{mL}$ had the greatest PLC risk, that is to say, greater than 
Table 2. Incidence rates of PLC and other main incident cancer types in HBsAg positive and HBsAg negative sub-cohort with calculation of incidence rate ratios and hazard ratios

\begin{tabular}{|c|c|c|c|c|c|c|c|c|c|c|c|c|}
\hline \multirow[t]{2}{*}{$\begin{array}{l}\text { Cancer } \\
\text { site }\end{array}$} & \multicolumn{3}{|c|}{$\begin{array}{l}\text { HBsAg positive } \\
(n=852)\end{array}$} & \multicolumn{3}{|c|}{$\begin{array}{l}\text { HBsAg negative } \\
(n=786)\end{array}$} & \multirow[t]{2}{*}{ IR ratios } & \multirow[t]{2}{*}{$95 \% \mathrm{Cl}$} & \multirow[t]{2}{*}{$P$ value } & \multirow[t]{2}{*}{ HR } & \multirow[t]{2}{*}{$95 \% \mathrm{Cl}$} & \multirow[t]{2}{*}{$P$ value } \\
\hline & $\bar{n}$ & PY & $\underset{\left(n / 10^{5}\right)}{\mathrm{IR}}$ & $n$ & PY & $\underset{\left(n / 10^{5}\right)}{\operatorname{IR}}$ & & & & & & \\
\hline Liver & 187 & 16,853 & 1110 & 14 & 17,680 & 79 & 12.32 & $7.16-21.21$ & $<0.0001$ & 14.00 & $8.13-24.1$ & $<0.0001$ \\
\hline Lung & 11 & 17,270 & 64 & 22 & 17,679 & 124 & 0.46 & $0.22-0.95$ & 0.0361 & 0.53 & $0.26-1.08$ & 0.0815 \\
\hline Gastric & 12 & 17,242 & 70 & 11 & 17,649 & 62 & 1.01 & $0.44-2.28$ & 0.9878 & 1.10 & $0.49-2.49$ & 0.8214 \\
\hline Colorectal & 2 & 17,230 & 12 & 7 & 17,673 & 40 & 0.26 & $0.05-1.27$ & 0.0963 & 0.15 & $0.02-1.20$ & 0.0736 \\
\hline Pancreatic & 5 & 17,261 & 29 & 3 & 17,695 & 17 & 1.54 & $0.37-6.43$ & 0.5558 & 1.80 & $0.43-7.51$ & 0.4231 \\
\hline Esophagus & 1 & 17,276 & 6 & 6 & 17,690 & 34 & 0.15 & $0.02-1.28$ & 0.0830 & 0.17 & $0.02-1.42$ & 0.1022 \\
\hline Bladder & 2 & 17,272 & 12 & 3 & 17,692 & 17 & 0.62 & $0.10-3.78$ & 0.5944 & 0.71 & $0.12-4.27$ & 0.7099 \\
\hline Others & 11 & 17,251 & 64 & 9 & 17,685 & 51 & 1.13 & $0.47-2.72$ & 0.7894 & 1.29 & $0.54-3.12$ & 0.5696 \\
\hline
\end{tabular}

PLC: primary liver cancer; HBsAg: hepatitis B surface antigen; PY: person years; IR: incidence rate; Cl: confidence interval; HR: hazard ratio

those with serum HBV DNA more than $10^{6}$ copies $/ \mathrm{mL}^{[33]}$. This observation was discrepant with results from Taiwan $^{[34]}$, but consistent with the results from another cohort study in Qidong ${ }^{[35]}$.

\section{HBV variations and hepatocellular carcinoma}

HBV DNA mutation has been considered to be linked with hepatocellular carcinoma $(\mathrm{HCC})^{[36]}$. However, this relationship had never been evaluated in Qidong before we initiated a series of studies concerning HBV variation and the sequelae of $\mathrm{HBV}$ infection. By using the plasma samples from the members of the QBC, we found the A1762T/G1764A double mutation of the HBV basal core promoter (BCP) was frequently detected in HBV infected participants ${ }^{[16]}$. However, the A1762T/G1764A double mutation alone was not sufficient to produce a statistically significant association with PLC. We reported, for the first time, that it was the triple or quadruple mutation occurring at nucleotide positions 1762, 1764, 1766 and 1768 that played roles in the development of PLC. While the odd ratio of PLC patients with the A1762T/G1764A double mutation alone was 0.393 (95\% CI: 0.234-0.660), it increased to 1.861 (95\% CI: 1.161-2.984) with the triple mutation and to 4.434 (95\% CI: $1.630-12.063)$ with the quadruple mutation in BCP region ${ }^{[18]}$. Functional studies revealed that the triple mutation could largely abrogate the colony inhibitory activity of $\mathrm{HBx}$, suggesting that the enhanced risk of HCC caused by BCP variants could be attributable to the aberrant activity of HBx. These results highlight the importance of the cumulative effects of BCP mutations on PLC risk ${ }^{[19]}$.

By sequencing the HBV genome, we identified and validated a series of novel PLC-related mutations. These mutations include A2159G, A2189C and G2203W at C gene ${ }^{[23]}$, A799G, A987G and T1055A at P gene $e^{[24]}$, and A1479T at X gene ${ }^{[18]}$. By using capillary gel electrophoresis, we found that it was the short fragment, rather than larger fragment, contributing to the association of Pre-S deletion with $\mathrm{HCC}^{[26,27]}$. In addition to the above novel findings, we also verified the association of some known HBV mutations, such as HBV pre-S2 start codon mutation ${ }^{[21]}$, C1653T and T1753C ${ }^{[19]}$, with HCC in Qidong.

Taking advantage of serial plasma samples collected from patients between chronic hepatitis B and manifestation of PLC, we were able to report the temporal order of HBV mutation during the course of PLC development. While A1762T/G1764A, C1653T, A799G, A987G, T1055A, pre-S deletion could be detected in the plasma long before PLC diagnosis, T1753C, C1766T and T1768A mutations appeared only one or two years before PLC diagnosis ${ }^{[1,20,23]}$. These observations provide valuable information for HCC prediction and screening when using HBV mutations as the marker.

\section{Aflatoxin exposure, P53 mutation and PLC}

Aflatoxin's role in PLC epidemic were also evaluated in Qidong, after an important cohort study in Shanghai ${ }^{[37]}$, by both nested case-control and cohort analysis in the $\mathrm{QBC}^{[38]}$. P53 G249T mutation is an indicator of aflatoxin exposure. The high prevalence of this mutation suggests aflatoxin as an important etiological factor of HCC in Qidong ${ }^{[39]}$. P53 mutations were determined initially in surgical resection tissues 
from PLC cases ${ }^{[40]}$. It was found that around 50\% of PLC cases in Qidong had a G to T transversion at the third position of codon 249 in the P53 gene. Consistent with the results in PLC tissues, the codon 249 mutation of P53 was also detected in $46.7 \%$ of the plasma samples from PLC patients ${ }^{[41]}$. Moreover, this mutation was detected at least 1 year prior to diagnosis in the plasma samples of 4 of 8 cases, suggesting P53 mutation could be an early biomarker for PLC ${ }^{[42]}$. We also have found that PLC risk increased with the elevated concentration of serum AFB1-albumin adducts, which is a direct biomarker for aflatoxin exposure. Lastly, a sharp decline in the age-standardized rate of PLC documented by the QCR has occurred subsequent to a population-scale change in dietary food stuff from maize to corn in the 80s and 90s. The concomitant more than 1000-fold decline in aflatoxin exposures has occurred well before the implementation of a universal vaccination program against $\mathrm{HBV}$ in this region ${ }^{[43]}$.

\section{WHAT ARE THE MAIN STRENGTHS AND WEAKNESS OF THE STUDY?}

The main strengths of the QBC are: (1) The QBC is a cohort study with long-term and continuous follow-up, as well as a very low rate of attrition. To our knowledge, this is a community-based HBV infected cohort with the longest period of observation worldwide. During the past two decades, the participants of the cohort have been followed up once or twice each year, which has produced continuous data for research on PLC etiology. The high quality data from cancer registry and vital statistics of Qidong lend confidence and perspective to the results. (2) The QBC database comprises a large amount of clinical and laboratory information. Structured questionnaires were implemented first in 1998 and updated in 2012, which alleviates concerns that the exposure status of related factors such as smoking and drinking could have changed during the past two decades. Serum viral and biochemical indicators such as HBsAg, AFP, and ALT at each round of follow up have been measured by the consistent kits from KHB Company to make longitudinal analysis possible as is the case with other examination such as abdominal ultrasonography. Although HBV DNA load, $\mathrm{HBe} A g, \mathrm{HBV}$ genotype and HBV common mutations were not tested at baseline, they were examined using archived plasma collected at baseline and from the year when PLC was diagnosed. (3) The bio-sample bank based on this cohort now has serial plasma, white cell and urine samples. Such valuable samples collected before and after diagnosis of PLC provide a superior opportunity for evaluation of novel diagnostic markers of PLC. Indeed, key findings mentioned above were facilitated by availability of longitudinal collection of plasma samples. To our knowledge, such community-based HBV infected cohorts usually have only baseline blood samples for each participant. The characteristic of serial samples is exceptional. (4) Although the QBC is not a large scale cohort, it has already generated 201 PLC cases. This number has surpassed any others of its kind and will meet the needs of any sophisticated statistical analysis related to the study of PLC etiology and prognosis.

\section{CAN I GET HOLD OF THE DATA? WHERE CAN I FIND OUT MORE?}

The QBC study offers a unique opportunity to further research. Data collection documents and bio-samples are stored at QDLCI and SCI. We encourage interested research teams to make contact with our current leader and chief investigator of this cohort, Dr. Tao-Yang Chen, at E-mail: ty110@263.net, and Dr. Hong Tu, at E-mail: tuhong@shsci.org.

\section{DECLARATIONS}

\section{Acknowledgments}

We thank Dr. Yawei Zhang from Yale University School of Public Health for her help in the manuscript preparation. The contribution to data collection made by local physicians, nurses, ultrasound doctors, interviewers and laboratory staff is greatly and sincerely acknowledged. The authors are also appreciative of all the senior researchers who have ever worked in the "Qidong high incidence scene of liver cancer". Only with their outstanding efforts contributed in the earlier years, could it be realistic for a following generation of 
investigators to continue. Last but not least, we thank all the study participants whose longstanding personal dedication and commitment have been paramount to make this study possible.

\section{Authors' contributions}

Current co-principle investigators of QBC: Chen TY, Tu H

Former co-principle investigators of QBC: Qian GS, Lu PX

Cohort maintenance and data collection: Sun Y, Wang JB, Lu PX, Xue XF, Wu Y, Zhang QN, Lu JQ

Molecular and biochemistry experiments of QBC: Jin Y, Wu YQ, Gan Y

Collaborative researches on aflatoxin and HBV: Kensler TW, Groopman JD

Cleaned raw data, performed statistical analysis and wrote the preliminary manuscript: Fan CS

Revised the manuscript and added important intellectual contents into the manuscript: Chen TY, Qian GS, $\mathrm{Tu} \mathrm{H}$

\section{Data source and availability}

Data collection documents and bio-samples are stored at QDLCI and SCI. Interested research teams can contact with Dr. Tao-Yang Chen at E-mail: ty110@263.net, and Dr. Hong Tu at E-mail: tuhong@shsci.org.

\section{Financial support and sponsorship}

This work was supported by Chinese National Key Project of Eighth Five-year (grant number 859140303, GQ); Chinese National Key Project of Ninth Five-year (grant number 969060107, GQ); Chinese National Key Project Specialized for Infectious Diseases (grant numbers 2008ZX10002-015, HT; 2008ZX10002-018, TC; 2012ZX10002008-003, TC; 2012ZX10002-008-002, HT; 2017ZX10201201-006-002, TC; 2017ZX10201201-008003, HT); National Institute of Environmental Health Sciences grant PO1 (grant number ES06052 USA, JDG and TWK); Chinese National Key Research Projects for Precision Medicine (grant number 2017YFC0908103, JL); Research Funding for Young Medical Talents of Nantong Municipal Commission of Health and Family Planning (grant number WQZ2015007, CF).

\section{Conflict of interest}

There are no conflicts of interest.

\section{Patient consent}

All participants signed the informed consent before study.

\section{Ethics approval}

The study protocol and informed consent were approved by the human subjects review committees at the Qidong Liver Cancer Institute, Shanghai Cancer Institute and John Hopkins University.

\section{Copyright}

(c) The Author(s) 2018.

\section{REFERENCES}

1. Li JY, Liu BQ, Li GY, Chen ZJ, Sun XI, Rong SD. Atlas of cancer mortality in the People's Republic of China. An aid for cancer control and research. Int J Epidemiol 1981;10:127-33.

2. Chen JG, Zhu J, Parkin DM, Zhang YH, Lu JH, Zhu YR, Chen TY. Trends in the incidence of cancer in Qidong, China, 1978-2002. Int J Cancer 2006;119:1447-54.

3. Lu JH, Li WG, Jiang ZY, Ni ZP, Huang F. Prospective survey on relationship between HBsAg carrier status and liver cancer. $J$ Med Res $1983 ;(5): 13-4$.

4. Wei YP, Lu PX, Huang QS, Lu SX, Zhang QN, Gu JP. Prospective study with 518 participants on relationship between HBsAg status and liver cancer incidence. J Clin Hepatol 1992;8:77-8.

5. Wang YB, Lan LZ, Ye BF, Xu YC, Li WG. Study on relationship between geographical distribution of liver cancer, climate and 
aflatoxin B1. Tumor 1981;1:1-5.

6. Li WG, Xie JR, Yu SY, Chu YJ, Gong XL. Relationship between geographic distribution of primary liver cancer and selenium level in Qidong county. Trace Elements 1986;(3):58-61.

7. Liu PL, Su DL, Yu SZ, Li WG. HBV seroepidemiological study in population with different drinking water sources in Qidong county. Acta Acad Med Prim Shanghai 1985;12:427-34.

8. Chen JG. Liver cancer endemic trend between 1972 and 1981 in Qidong county. J Med Res 1983;(12):13-5.

9. Yang L, Parkin DM, Whelan S, Zhang S, Chen Y, Lu F, Li L. Statistics on cancer in China: cancer registration in 2002. Eur J Cancer Prev 2005;14:329-35.

10. Sun GJ, He X, Qian GS, Pu YP, Jin XP, Wang JS. Detecting urine aflatoxin metabolism by high performance liquid chromatography. $J$ Health Toxicol 2000;14:250-2.

11. Sun GJ, He X, Qian GS, Pu YP, Jin XP, Wang JS. Detection of aflatoxin-ablumin adducts in human serum and its application. Wei Sheng Yan Jiu 2001;30:185-7. (in Chinese)

12. Wu YQ, Wan SG, Lu PX, Wang JS, Kuang SY, Wang JB, Fang X, Wu Y, Zhang QN, Qu Q, Kensler T, Groopman J, Qian GS. Genotype of GSTT1 and GSTM1 among population in Qidong liver cancer high incidence field. Natl Med J China 1999;79:517-8.

13. Wu YQ, Lu PX, Wang JS, Wang JB, Wan SG, Kensler TW, Groopman JD, Qian GS. Correlation between the genetic polymorphism of EPHX and susceptibility to hepatocellular carcinoma. Tumor 2003;23:287-9.

14. Xu L, Wu YQ, Jin Y, Yu YM, Qian GS. A case-control study on polymorphism of DNA repair gene XPD and susceptibility to hepatocellular carcinoma. Tumor 2004;24:526-9.

15. Qian GS, Kuang SY, He X, Groopman JD, Jackson PE. Sensitivity of electrospray ionization mass spectrometry detection of codon 249 mutations in the p53 gene compared with RFLP. Cancer Epidemiol Biomarkers Prev 2002;11:1126-9.

16. Kuang SY, Jackson PE, Wang JB, Lu PX, Muñoz A, Qian GS, Kensler TW, Groopman JD. Specific mutations of hepatitis B virus in plasma predict liver cancer development. Proc Natl Acad Sci U S A 2004;101:3575-80.

17. Guo X, Jin Y, Qian GS, Xu L, Tu H. Full-genome sequence analysis of hepatitis B virus isolated from hepatocellular carcinoma in high incidence area Qidong. Tumor 2007;27:429-32.

18. Bai X, Zhu Y, Jin Y, Guo X, Qian G, Chen T, Zhang J, Wang J, Groopman JD, Gu J, Tu H. Temporal acquisition of sequential mutations in the enhancer II and basal core promoter of HBV in individuals at high risk for hepatocellular carcinoma. Carcinogenesis 2011;32:63-8.

19. Guo X, Jin Y, Qian G, Tu H. Sequential accumulation of the mutations in core promoter of hepatitis B virus is associated with the development of hepatocellular carcinoma in Qidong, China. J Hepatol 2008;49:718-25.

20. Bai X, Zhu Y, Jin Y, Cai X, Guo X, Qian G, Chen T, Zhang J, Wang J, Tu H. Correlation of the mutations in N terminal of hepatitis B virus X protein with tumorigenesis of hepatocellular carcinoma. Tumor 2010;30:433-7.

21. Cao Z, Bai X, Guo X, Jin Y, Qian G, Tu H. High prevalence of hepatitis B virus pre-S mutation and its association with hepatocellular carcinoma in Qidong, China. Arch Virol 2008;153:1807-12.

22. Zhu Y, Jin Y, Cai X, Bai X, Chen M, Chen T, Wang J, Qian G, Gu J, Li J, Tu H. Hepatitis B virus core protein variations differ in tumor and adjacent nontumor tissues from patients with hepatocellular carcinoma. Intervirology 2012;55:29-35.

23. Zhu Y, Jin Y, Guo X, Bai X, Chen T, Wang J, Qian G, Groopman JD, Gu J, Li J, Tu H. Comparison study on the complete sequence of hepatitis B virus identifies new mutations in core gene associated with hepatocellular carcinoma. Cancer Epidemiol Biomarkers Prev 2010;19:2623-30.

24. Wu Y, Gan Y, Gao F, Zhao Z, Jin Y, Zhu Y, Sun Z, Wu H, Chen T, Wang J, Sun Y, Fan C, Xiang Y, Qian G, Groopman JD, Gu J, Tu H. Novel natural mutations in the Hepatitis B Virus reverse transcriptase domain associated with hepatocellular carcinoma. PLoS One 2014;9:1-10.

25. Gao FM, Wu Y, Zhao ZM, Jin Y, Qian GS, Chen TY, Zhang YW, Wang JB, Gan Y, Xiang YB, Tu H. The association between mutations in the reverse transcriptase domain of hepatitis B virus polymerase gene with tumorigenesis of hepatocellular carcinoma. Tumor 2014;34:141-6.

26. Zhao ZM, Zhu Y, Wu Y, Fan CS, Chen TY, Gan Y, Tu H. Development and application of a reverse hybridization method for detection of hepatitis B virus precore mutation associated with hepatocellular carcinoma. China Oncol 2014;24:266-72.

27. Zhao ZM, Jin Y, Gan Y, Zhu Y, Chen TY, Wang JB, Sun Y, Cao ZG, Qian GS, Tu H. Novel approach to identifying the hepatitis B virus pre-S deletions associated with hepatocellular carcinoma. World J Gastroenterol 2014;20:13573-81.

28. Lu P, Kuang S, Wang J, Fang X, Zhang Q, Wu Y, Lu Z, Qian G. Hepatitis B virus infection and aflatoxin exposure in the development of primary liver cancer. Natl Med J China 1998;78:340-2.

29. Lu P, Zhang Q, Huang Q, Wei Y. The HBV and HCV infection rates among various populations in high incidence area of hepatocellular carcinoma (HCC) and their relationship with HCC. Tianjin Med J 1999;27:6-7.

30. Lu P, Wang J, Wu Y, Zhang Q, Wu Y, Wan S, Kuang S, Wang N, Qian G. Significance of prospective follow-up cohort study in diagnosis and treatment of primary hepatic cancer among HBsAg carriers. Natl Med J China 2001;81:856-9.

31. Sun Y, Lu P, Wang J, Wu Y, Zhang Q, Chen T. A prospective study of the relationship between hepatitis B virus markers and primary liver cancer. Tianjin Med J 2010;38:81-3.

32. Sun Y, Chen T, Lu P, Wang J, Wu Y, Zhang Q, Jin Y, Qian G, Tu H. A seventeen-year prospective cohort study on association of hepatitis B virus e antigen with the risk of hepatocellular carcinoma. Tumor 2011;31:841-5.

33. Sun Y, Chen T, Lu P, Wang J, Wu Y, Zhang Q, Qian G, Tu H. Relationship between serum hepatitis B virus DNA load and hepatocellular carcinoma in Qidong, China: a cohort follow-up study of 14 years. Natl Med J China 2012;92:1874-7. 
34. Iloeje UH, Yang HI, Chen CJ. Natural history of chronic hepatitis B: what exactly has REVEAL revealed? Liver Int 2012;32:1333-41.

35. Liu TT, Fang Y, Xiong H, Chen TY, Ni ZP, Luo JF, Zhao NQ, Shen XZ. A case-control study of the relationship between hepatitis B virus DNA level and risk of hepatocellular carcinoma in Qidong, China. World J Gastroenterol 2008;14:3059-63.

36. Liu S, Zhang H, Gu C, Yin J, He Y, Xie J, Cao G. Associations between hepatitis B virus mutations and the risk of hepatocellular carcinoma: a meta-analysis. J Natl Cancer Inst 2009;101:1066-82.

37. Qian GS, Ross RK, Yu MC, Yuan JM, Gao YT, Henderson BE, Woqan GN, Groopman JD. A follow-up study of urinary markers of aflatoxin exposure and liver cancer risk in Shanghai, People's Republic of China. Cancer Epidemiol Biomarkers Prev 1994;3:3-10.

38. Lu P, Wang J, Zhang Q, Wu Y, Sun Y, Chen T. Longitudinal study of aflatoxin exposure in the development of primary liver cancer in patients with chronic hepatitis. Natl Med J China 2010;90:1665-9.

39. Jackson PE, Qian GS, Friesen MD, Zhu YR, Lu P, Wang JB, Wu Y, Kensler TW, Vogelstein B, Groopman JD. Specific p53 mutations detected in plasma and tumors of hepatocellular carcinoma patients by electrospray ionization mass spectrometry. Cancer Res 2001;61:33-5.

40. Luo H, Wan S, Lu P, Liu Y, Wang J, Jin Y, Wu Y, Qian G. The p53 overexpression in Qidong liver cancer tissues analysed immunohistochemically. Tumor 2002;22:101-3.

41. Rashid A, Wang JS, Qian GS, Lu BX, Hamilton SR, Groopman JD. Genetic alterations in hepatocellular carcinomas: association between loss of chromosome 4q and p53 gene mutations. Br J Cancer 1999;80:59-66.

42. Jackson PE, Kuang SY, Wang JB, Strickland PT, Muñoz A, Kensler TW, Qian GS, Groopman JD. Prospective detection of codon 249 mutations in plasma of hepatocellular carcinoma patients. Carcinogenesis 2003;24:1657-63.

43. Chen JG, Egner PA, Ng D, Jacobson LP, Muñoz A, Zhu YR, Qian GS, Wu F, Yuan JM, Groopman JD, Kensler TW. Reduced aflatoxin exposure presages decline in liver cancer mortality in an endemic region of China. Cancer Prev Res (Phila) 2013;6:1038-45. 